\title{
Novel Insights into Selection for Antibiotic Resistance in Complex Microbial Communities
}

\author{
(D) Aimee K. Murray, ${ }^{a}$ Lihong Zhang, ${ }^{a}$ Xiaole Yin, ${ }^{b}$ Tong Zhang, ${ }^{b}$ Angus Buckling, ${ }^{c}$ Jason Snape, ${ }^{d}$ William H. Gaze ${ }^{a}$ \\ aEuropean Centre for Environment and Human Health, University of Exeter Medical School, Environment \& \\ Sustainability Institute, Penryn, Cornwall, United Kingdom \\ bDepartment for Civil Engineering, University of Hong Kong, Hong Kong, China \\ 'College of Life and Environmental Sciences, University of Exeter, Penryn, Cornwall, United Kingdom \\ dAstraZeneca Global Environment, Macclesfield, Cheshire, United Kingdom
}

\begin{abstract}
Recent research has demonstrated that selection for antibiotic resistance occurs at very low antibiotic concentrations in single-species experiments, but the relevance of these findings when species are embedded in complex microbial communities is unclear. We show that the strength of selection for naturally occurring resistance alleles in a complex community remains constant from low subinhibitory to above clinically relevant concentrations. Selection increases with antibiotic concentration before reaching a plateau where selection remains constant over a 2-order-magnitude concentration range. This is likely to be due to cross protection of the susceptible bacteria in the community following rapid extracellular antibiotic degradation by the resistant population, shown experimentally through a combination of chemical quantification and bacterial growth experiments. Metagenome and $16 \mathrm{~S}$ rRNA analyses of sewage-derived bacterial communities evolved under cefotaxime exposure show preferential enrichment for bla $_{\mathrm{CTX}-\mathrm{M}}$ genes over all other beta-lactamase genes, as well as positive selection and co-selection for antibiotic resistant, opportunistic pathogens. These findings have far-reaching implications for our understanding of the evolution of antibiotic resistance, by challenging the longstanding assumption that selection occurs in a dose-dependent manner.
\end{abstract}

IMPORTANCE Antibiotic resistance is one of the greatest global issues facing society. Still, comparatively little is known about selection for resistance at very low antibiotic concentrations. We show that the strength of selection for clinically important resistance genes within a complex bacterial community can remain constant across a large antibiotic concentration range (wide selective space). Therefore, largely understudied ecological compartments could be just as important as clinical environments for selection of antibiotic resistance.

KEYWORDS antibiotic resistance, evolution, metagenomics, microbial ecology

A ntibiotic resistance poses a major threat to society, the sustainability of modern health care systems, food security, and the global economy $(1,2)$. Until recently, most research on evolution of resistance focused on selection at clinically relevant antibiotic concentrations, as the "traditional" selective window hypothesis was universally accepted. This hypothesis states that selection for antibiotic resistance will occur only above the MIC of susceptible bacteria and below the MIC of resistant bacteria (3). In fact, numerous experimental studies have observed selection for resistance at sub-MIC antibiotic concentrations, at the point where the selective pressure (antibiotic) is sufficient to offset the cost of resistance (3-7). In recent isogenic studies, a single host species with chromosomal or plasmid-borne resistance mechanisms was competed with its susceptible counterpart at various concentrations of antibiotic to determine the
Received 14 May 2018 Accepted 18 June 2018 Published 24 July 2018 Citation Murray AK, Zhang L, Yin X, Zhang T, Buckling A, Snape J, Gaze WH. 2018. Novel insights into selection for antibiotic resistance in complex microbial communities. mBio 9:e00969-18. https://do .org/10.1128/mBio.00969-18.

Editor Joanna B. Goldberg, Emory University School of Medicine

Copyright $\odot 2018$ Murray et al. This is an open-access article distributed under the terms of the Creative Commons Attribution 4.0 International license. Address correspondence to Aimee K. Murray, a.k.murray@exeter.ac.uk, or William H. Gaze, w.h.gaze@exeter.ac.uk. 
minimal selective concentration (MSC) $(3,5)$. The MSC is the lowest concentration of antibiotic at which resistance is positively selected, which can be significantly lower than the MIC $(3,5)$. MSCs have also been estimated using publicly available, clinical breakpoint data (8), but experimental data are required to assess the validity of these predictions, especially in a community context. These findings show that the selective compartment (the antibiotic gradient and spatial range along which resistant bacteria/genes could be enriched) is much larger than previously thought (9). This in turn suggests that selection may be occurring in previously unconsidered selective compartments which harbor relatively low antibiotic concentrations, such as the gut microbiome, wastewater, and even surface waters contaminated with antibiotic residues.

Though these findings are significant, the use of single species means that their relevance with regard to selection in complex microbial communities remains unclear. Many studies have quantified numbers and/or prevalence of resistance genes in wastewater influent and effluent (including, but not limited to, references 10 and 11), with a recent study utilizing emulsion, paired isolation, and concatenation PCR (epicPCR) to identify the host background of highly abundant resistance genes (12). However, positive selection for resistance within complex bacterial communities is a current knowledge gap (13), with experimental MSC data in complex communities severely lacking. One recent study (14) reported a biological effect at low concentrations of tetracycline in a microbial community, by quantifying tetracycline resistance gene prevalence (tet $A$ and tet $G$ genes normalized to $16 \mathrm{~S}$ rRNA copy number). However, as starting gene frequencies were not measured, it is unclear if the observed effect was driven by positive selection or reduced negative selection. In other words, without comparing the final resistance gene prevalence to the initial resistance gene prevalence, it is unknown if resistance genes actually increased over time under tetracycline exposure (i.e., were positively selected) or if resistance genes were simply lost at a lower rate than the no-antibiotic control (i.e., were negatively selected or showed increased persistence). Here, we aimed to quantify positive selection in a complex bacterial community by conducting evolution experiments using a wastewater bacterial community inoculum to determine the MSC of cefotaxime. Co-selection for other resistance genes and effects on community structure were also determined through metagenome analyses.

Cefotaxime is a World Health Organization (WHO) recognized "critically important" antibiotic (15) "essential" for human medicine (16) that was most recently identified as a key antimicrobial stewardship target through inclusion in the WHO "watch list" of essential medicines (17). In this study, the prevalence of the bla $a_{\mathrm{CTX}-\mathrm{M}}$ gene group was determined with quantitative PCR ( $\mathrm{PPCR}$ ) and selection coefficients were calculated to estimate the MSC of cefotaxime. CTX-Ms are extended-spectrum beta-lactamases (ESBLs) which cleave the beta-lactam ring, effectively inactivating and degrading beta-lactam antibiotics (18). Previous work has demonstrated that beta-lactamases can inactivate extracellular beta-lactams, to the benefit of nearby susceptible bacteria (19-21). This protective effect on susceptible bacteria has since been shown for an intracellularly expressed resistance mechanism, also degradative in nature (22).

Results show, for the first time, that selection for bla $a_{\text {CTX-M }}$ genes occurs at very low, subinhibitory concentrations. We also demonstrate that selection occurs with equal potency at very low antibiotic concentrations and at concentrations greatly exceeding those used in the clinic. Therefore, antibiotic resistance is not always selected for in a dose-dependent manner. These findings illustrate the importance of studying selection for resistance within complex bacterial communities over a wide selective range, representative of different selective compartments (9).

\section{RESULTS}

Cefotaxime exposure affects community structure. Complex community (raw, untreated wastewater) microcosms were spiked with a range of cefotaxime concentrations. The exposure concentration range was selected from the EUCAST (23) defined 

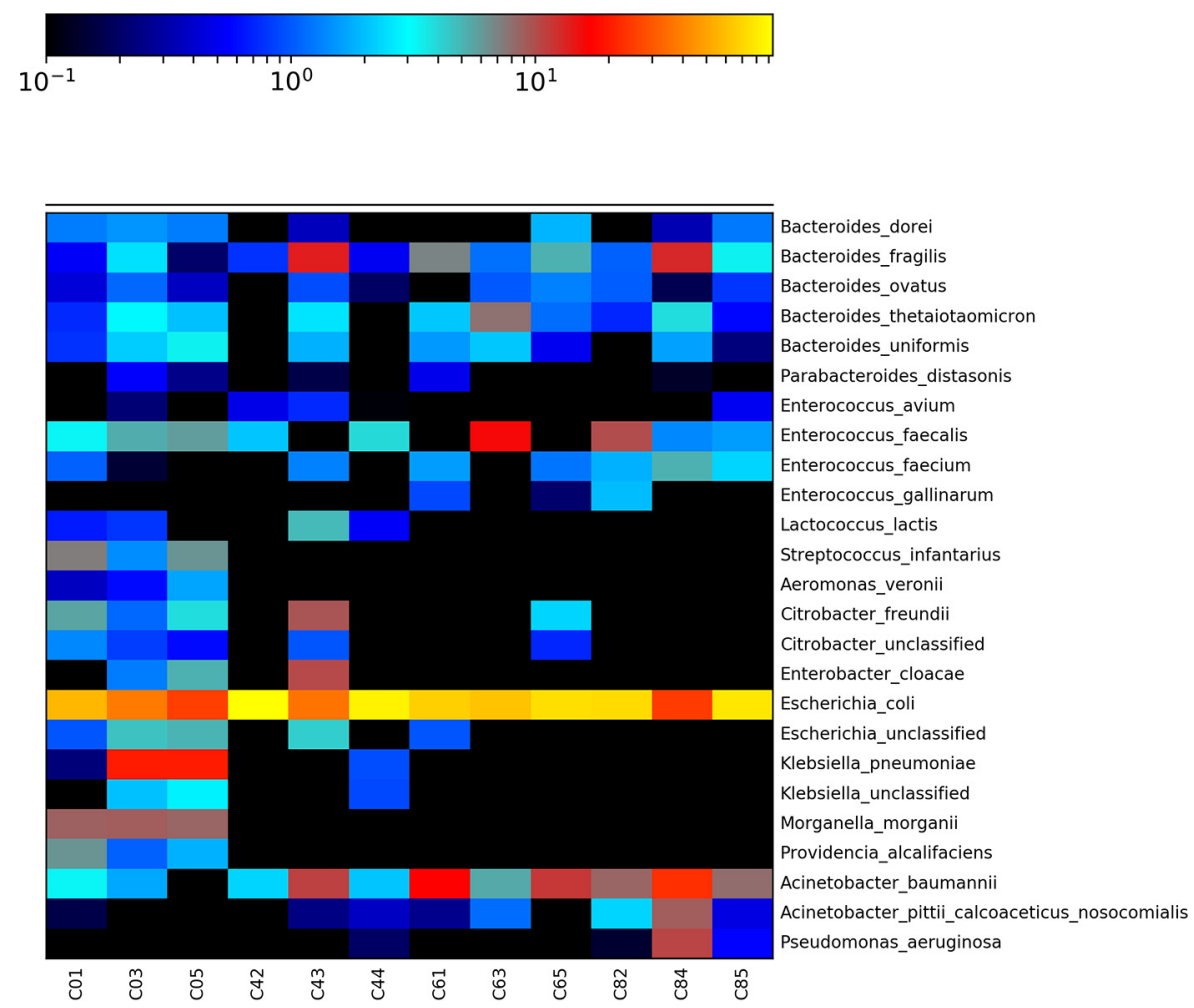

FIG 1 Heat map showing the relative abundance of detected species using Bray-Curtis distance measurements for treatment ( $x$ axis) and species ( $y$ axis) for each cefotaxime treatment. " $\mathrm{C} 0$," " $\mathrm{C} 4$," " $\mathrm{C} 6$," and " $\mathrm{C} 8$ " correspond to 0,125 , and $500 \mu \mathrm{g} /$ liter and $2 \mathrm{mg} /$ liter cefotaxime, respectively. The number after the concentration denotes the biological replicate number ( 1 to 5 ), chosen randomly for sequencing at day 8 of the experiment.

clinical breakpoint concentration (the concentration at which Enterobacteriaceae are considered "clinically" resistant) down to 0 , in a 2 -fold dilution series including concentrations similar to those previously measured in different environments (such as hospital effluent, wastewater treatment plant effluent, and surface waters [few micrograms/liter up to $150 \mu \mathrm{g} /$ /iter \{24-26\}]). Bacterial communities were transferred daily into fresh medium and fresh antibiotic for 8 days. Chemical quantification was performed at the beginning of day 0 and after $24 \mathrm{~h}$, to determine an accurate MSC (based on measured rather than nominal antibiotic concentration) and to assess the chemical stability of cefotaxime (a third-generation cephalosporin of the beta-lactam class of antibiotics) in the system.

At the end of the experiment, three replicates from a low, medium, and high antibiotic concentration were selected to undergo metagenome analyses alongside the unexposed control to identify the key resistance genes under selection. Metagenome DNA was sequenced with an Illumina MiSeq2 sequencer.

16S rRNA data were extracted from trimmed, quality-controlled paired reads with MetaPhIAn2 (27). Overall, the community comprised predominantly Gram-negative bacteria, though Gram-positive bacteria were also detected (see Fig. S1 in the supplemental material). Between-sample variation was expected due to unavoidable heterogeneity within the complex community inoculum. Even so, there were clear differences between the control untreated bacterial community and the communities exposed to cefotaxime among the 25 most abundant species (Fig. 1; all detected species can be seen in Fig. S1). In particular, several species were eliminated by cefotaxime treatment (or reduced below the limit of detection). These included the opportunistic Gramnegative pathogens Providencia alcalifaciens, Aeromonas veronii, Morganella morganii, and Klebsiella pneumoniae, as well as the opportunistic Gram-positive pathogen Streptococcus infantarius. All of these were significantly associated with the no-antibiotic 


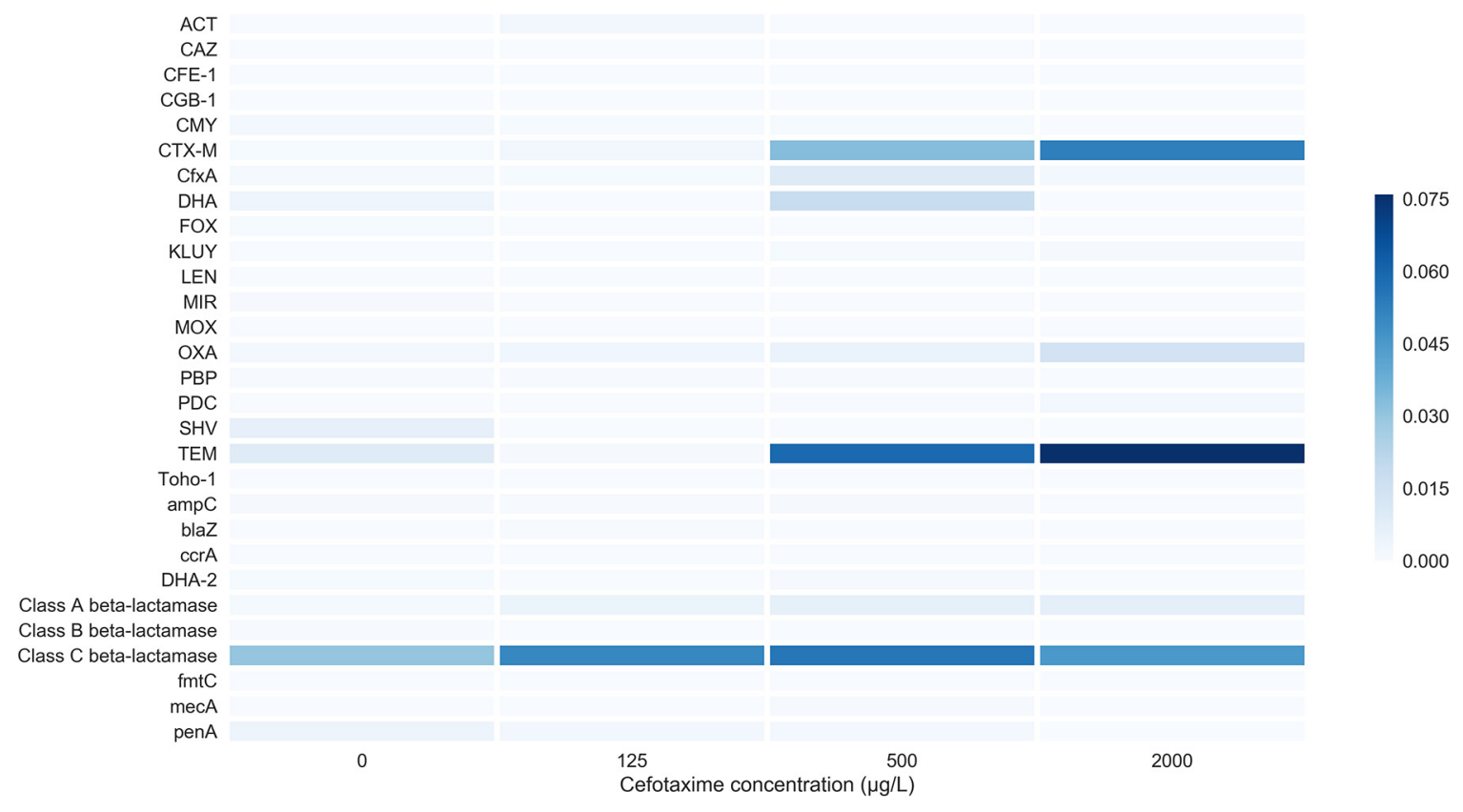

FIG 2 Heat map showing average $(n=3)$ detected beta-lactam resistance gene subtype relative abundance (resistance gene number normalized with $16 \mathrm{~S}$ rRNA copy number), following 8 days of culture with cefotaxime. Only genes detected with the ARGs-OAP pipeline are shown.

control as determined by linear discriminant analysis (LDA) effect size (LEfSe) analyses (Fig. S2). Conversely, several Gram-negative and Gram-positive opportunistic pathogens showed greater abundance in treated communities than in the untreated control, namely, Pseudomonas aeruginosa, Acinetobacter baumannii, Bacteroides fragilis, and Enterococcus faecalis; however, only P. aeruginosa was significantly enriched in the 2 $\mathrm{mg} /$ liter cefotaxime treatment (LEfSe, Fig. S2). Cefotaxime treatment also resulted in slightly decreased numbers of Escherichia coli, though this was not significant and it was still the predominant species across all treatments. In general, there was much greater variability between treatment replicates compared to the untreated control (Fig. S1).

bla $_{\text {CTX-M }}$ genes are preferentially selected over all other beta-lactam resistance mechanisms. Metagenome data were further analyzed with the ARGs-OAP pipeline (28), designed to thoroughly interrogate metagenome data and identify resistance genes. Selection for beta-lactam resistance was prominent (as expected); however, co-selection for resistance to unrelated antibiotic classes was also observed, namely, co-selection for resistance to macrolides, aminoglycosides, trimethoprim, tetracyclines, and sulfonamides, which is likely to be due to carriage of multiresistance plasmids (see Fig. S3).

We delved deeper into the beta-lactam resistance genes to determine which genes, if any, were preferentially selected. We observed substantial enrichment for the betalactamase and extended-spectrum beta-lactamase (ESBL) genes $b / a_{\mathrm{TEM}^{\prime}} b l a_{\mathrm{OXA}^{\prime}}$ and $b l a_{\text {CTX-M }}$ (Fig. 2). Average increases in relative abundance from the lowest to highest concentration were 8 -fold, 8-fold, and 70-fold, respectively. bla $a_{\text {CTX-M }}$ was preferentially selected over all other beta-lactamase-encoding genes at each cefotaxime concentration.

The MSC of cefotaxime is very low, but selection plateaus across a large concentration range. Given the strong positive selection for bla $a_{\text {СтX-M }}$, we focused on accurate quantification of this group of genes across the entire experimental antibiotic gradient using $\mathrm{QPCR}$. This follows previous work which showed that $\mathrm{QPCR}$ is the most sensitive method for MSC determination (14). bla $a_{C T X-M}$ gene copy number was normalized to $16 \mathrm{~S}$ rRNA copy number, to determine a molecular prevalence of $b / a_{\text {CTX-M; }}$ this 


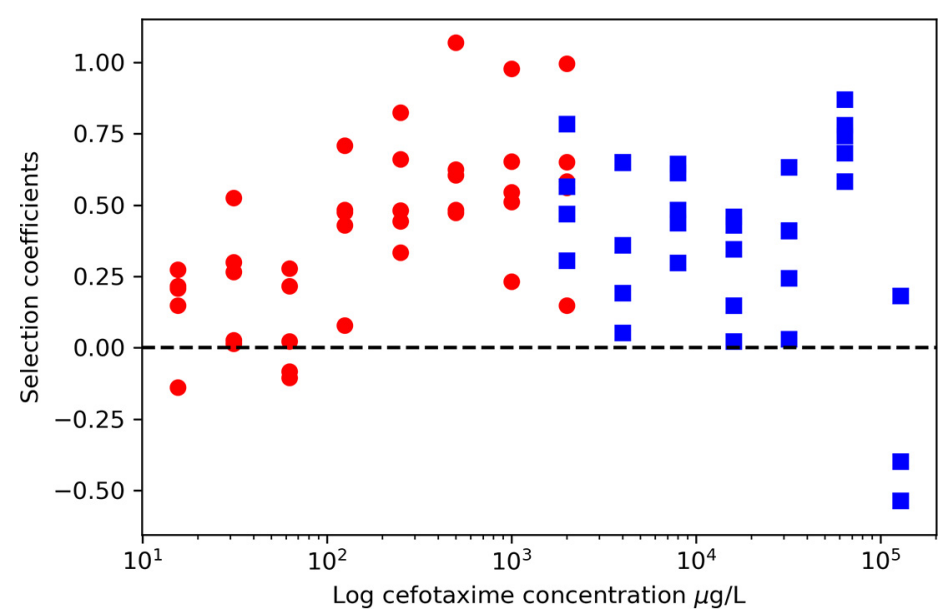

FIG 3 Selection coefficients $(n=5)$ for each cefotaxime concentration, which equal the natural log of resistance gene prevalence (bla $a_{\text {CTX-M }}$ gene/16S rRNA copy number) at day 0 and day 8 . Circles, selection coefficients from low-concentration experiment; squares, selection coefficients from high-concentration experiment. Selection coefficients of $>0$ indicate positive selection.

prevalence was determined for each cefotaxime concentration at both the beginning and end of the experiment. A Kruskal-Wallis test confirmed that bla $a_{\text {СTX-M }}$ prevalence, $16 \mathrm{~S}$ rRNA copy number, and bla $a_{\text {Стх-м }}$ copy number (all $n=5$ each) did not differ significantly between treatments at day 0 .

Selection coefficients based on change in bla $a_{\text {СтX-M }}$ prevalence over time were calculated and plotted against cefotaxime concentration as in previous single-species assays (3,5) (Fig. 3). A positive selection coefficient value indicates that positive selection is occurring, and the $x$ axis intercept estimates the MSC, here $0.4 \mu \mathrm{g} /$ liter (Fig. S4).

bla $a_{\text {СTX-M }}$ prevalence increased over time (Fig. S5) and with antibiotic concentration (linear term: $F_{1}, 42=26.3, P<0.001$ ) but appeared to plateau at $500 \mu \mathrm{g} / \mathrm{liter}$ (quadratic term: $\left.F_{1}, 42=13.2, P<0.001\right)$, and so an additional experiment was performed to determine if this plateau continued at higher concentrations (Fig. 3). As hypothesized, bla $a_{\text {СтХ-M }}$ prevalence increased when exposed to cefotaxime (linear term: $F_{1}, 36=9.6$, $P<0.01$ ) but remained relatively constant (quadratic term: $\mathrm{F}_{1}, 36=9.4, P<0.01$ ) up until the two highest concentrations used in this study (Fig. 3). These concentrations are over 30 times and 50 times the defined clinical breakpoint cefotaxime concentration of $2 \mathrm{mg} /$ liter for Enterobacteriaceae. The rise in bla ${ }_{\text {СтX-м }}$ prevalence at $64 \mathrm{mg} / \mathrm{liter}$ was due to an increase in $b / a_{\text {СTX-M }}$ gene copy number, and the decrease at $128 \mathrm{mg} / \mathrm{liter}$ was due to a significant decrease in bla $a_{\text {СTX-M }}$ and slight reduction in $16 \mathrm{~S}$ rRNA copy number (Fig. S6 and S7).

The bacterial community readily degrades cefotaxime. We hypothesized that this plateau in selection was due to both the mechanism and sociality of the $b / a_{\text {СTX-M }}$ genes: as beta-lactamase enzymes can be found both intracellularly and extracellularly (21), the plateau in bla $a_{\mathrm{CTX}-\mathrm{M}}$ prevalence may be due to negative frequency-dependent selection (19). In other words, the more prevalent bla $a_{\text {Стх-м }}$ becomes, the lower its fitness as cefotaxime degradation is accelerated to the benefit of the entire community, including non-bla $a_{\mathrm{CTX}-\mathrm{M}}$-bearing competitors. To investigate if cefotaxime was degraded by the community, chemical quantification of cefotaxime in the presence of the community was performed. Incubating the microcosms for $24 \mathrm{~h}$ resulted in complete degradation of cefotaxime, at all but the highest concentration (Table S1). All measured concentrations were lower than expected, and the lowest concentration (15.625 $\mu \mathrm{g} /$ liter) was below the limit of detection at the beginning of the assay. Therefore, the MSC $(0.4 \mu \mathrm{g} /$ liter) is estimated based on nominal concentrations but in reality is likely to be lower still. As cefotaxime is known to be relatively unstable (29), an overnight degradation experiment was conducted to determine the amount of biotic and abiotic 

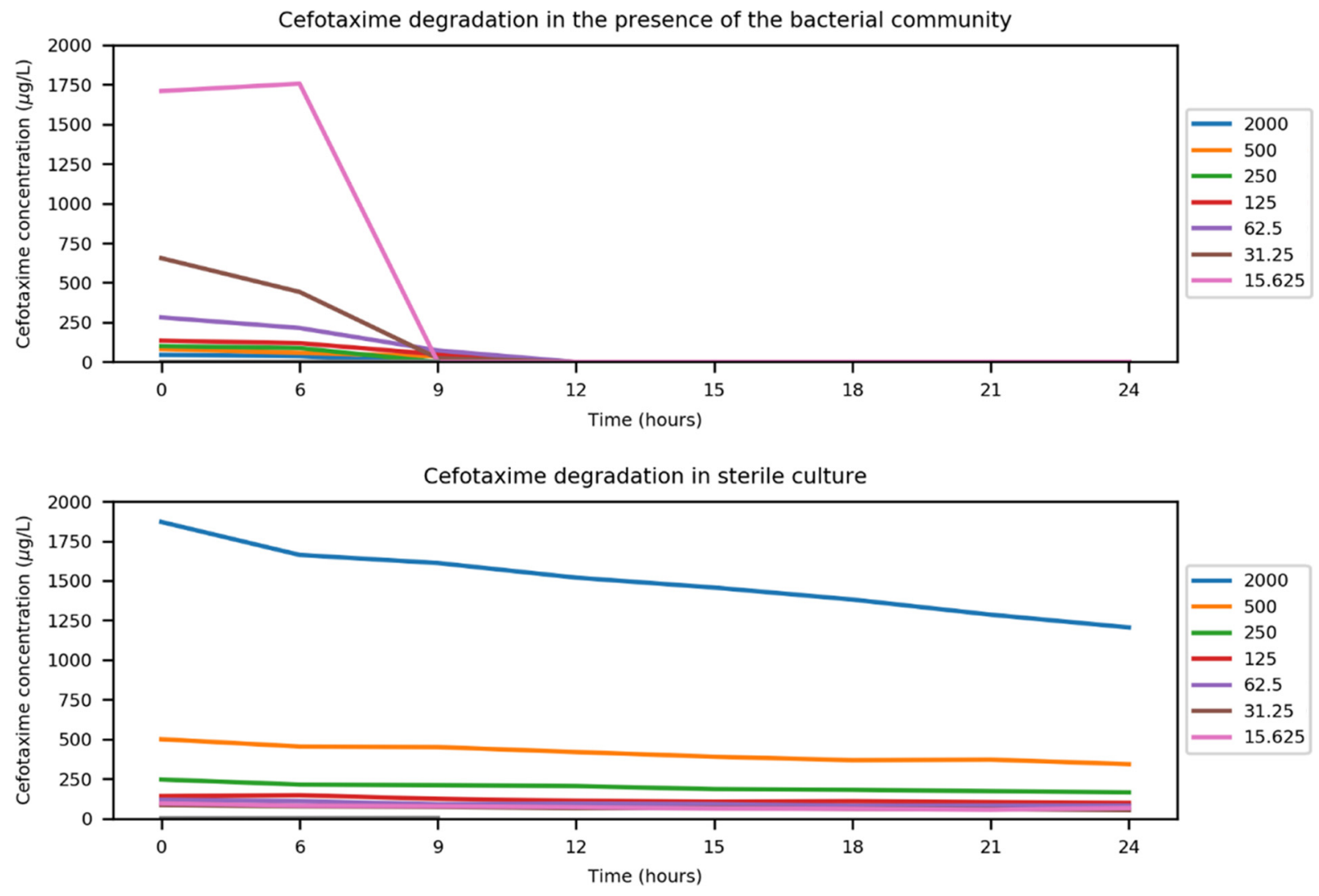

FIG 4 Single biological replicate and duplicate chemical replicate quantification of cefotaxime (measured cefotaxime concentration $\mu \mathrm{g} /$ liter) at 0 and $6 \mathrm{~h}$ and then every $3 \mathrm{~h}$ for $24 \mathrm{~h}$ at different starting cefotaxime concentrations (micrograms/liter) in the presence of the complex bacterial community and in sterile culture.

degradation occurring in the experimental system. A sterile microcosm and another inoculated with the complex community were incubated and destructively sampled at $0 \mathrm{~h}, 6 \mathrm{~h}$, and then every $3 \mathrm{~h}$ for $24 \mathrm{~h}$. In sterile culture, cefotaxime had only partially degraded over $24 \mathrm{~h}$, whereas in the presence of the community, cefotaxime was undetectable following $12 \mathrm{~h}$ of incubation (Fig. 4). This increase in degradation rate coincided with the beginning of the exponential growth phase of the community (Fig. S8).

Extracellular beta-lactamases "protect" susceptible bacteria at cefotaxime concentrations well above the MIC. To confirm that this degradation was biotic and by extracellular beta-lactamases, an additional experiment was performed whereby a susceptible E. coli strain (J53) was cultured in the presence of supernatant derived from an overnight culture of an $E$. coli strain bearing $b / a_{\mathrm{CTX}-\mathrm{M}^{-} 15}, b / a_{\mathrm{TEM}-1}$, and $b / a_{\mathrm{OXA}-1}$ on a fully sequenced resistance plasmid (30) (strain NCTC 13451, available from Public Health England). Addition of the supernatant from the resistant strain allowed growth of the susceptible strain at the clinical breakpoint concentration (23), which was over 10 times the MIC of the susceptible strain (Fig. 5).

\section{DISCUSSION}

Here, we quantified positive selection for antibiotic (cefotaxime) resistance in a wastewater-derived complex bacterial community, by quantifying changes in resistance gene prevalence over time. We show that clinically important (31) resistance genes $\left(b / a_{\mathrm{CTX}-\mathrm{M}}\right)$ were positively selected at very low, environmentally relevant concentrations likely due to a combination of clonal expansion of hosts carrying $b / a_{\text {CTX-M }}$ and horizontal gene transfer of plasmids bearing bla- ${ }_{\text {стх-м. }}$. Antibiotic quantification has been identified as an overlooked aspect of MSC determination (13). We quantified 


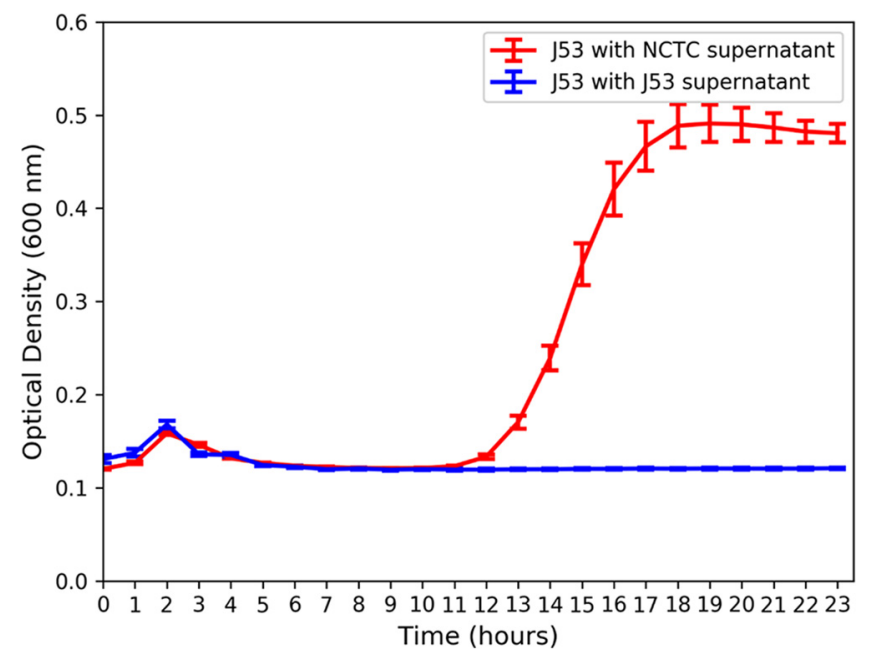

FIG 5 Average $(n=4)$ optical density $(600 \mathrm{~nm})$ over time of susceptible E. coli strain J53 grown in 2 mg/liter cefotaxime (clinical breakpoint concentration for Enterobacteriaceae) with beta-lactamasecontaining supernatant (NCTC strain 13451) or beta-lactamase-free supernatant (strain J53).

antibiotic concentrations when determining the MSC and found cefotaxime to be rapidly degraded by the community, suggesting the estimated MSC of $0.4 \mu \mathrm{g} /$ liter to be an underestimate. Even so, the cefotaxime MSC determined in this study was very similar to several measured environmental concentrations $(25,32)$, suggesting that selection could occur in certain environments such as hospital effluent and wastewater influent. Responses to selection in such environments may be reduced, as unenriched bacterial communities, e.g., in sewage, may be impacted by high cell numbers and associated reduction in resource availability. However, it is also possible that sustained exposure over long periods would produce the same response.

In addition, we observed a plateau in the strength of selection across a very large antibiotic concentration range. This novel finding contrasts with previous work which has shown resistance to increase monotonically with antibiotic concentration $(3,5,14)$. A crucial implication of this finding is that selection for clinically important resistance mechanisms, such as bla $a_{\mathrm{CTX}-\mathrm{M}}$ may occur to a similar extent at subinhibitory concentrations as at high, clinical concentrations. The observed plateau in resistance selection has clinical relevance, when considering the antibiotic concentration gradients which inevitably form in different body compartments during chemotherapy (33). These may also provide greater potential for selection for antibiotic resistance in vivo than previously considered. Potential overtreatment with unnecessarily long antibiotic courses (34) may compound this effect. Future research should address this finding and its relevance to environmental protection, effective antibiotic treatment, and antimicrobial stewardship.

The observed plateau in selection for resistance is likely due to the cross-protective effect conferred by the resistant fraction on the susceptible fraction of bacteria in the population. Three lines of evidence strongly support this: (i) the degradative effect of the community, whereby within $24 \mathrm{~h}$ all cefotaxime is degraded below the limit of chemical quantification, including the very highest, clinical breakpoint concentration; (ii) metagenome analyses of 3 replicates at 4 antibiotic concentrations, which showed that the main mechanism of resistance to the treatment antibiotic was degradative in nature and could therefore provide a benefit to susceptible competitors within the community; (iii) the single-species E. coli experiment, which used supernatant from a resistant strain bearing a multiresistance plasmid with the plasmid-free strain to show the potential extent of this community-wide benefit. The level of protection conferred by extracellular beta-lactamases in the supernatant of the resistant strain culture allowed growth of the susceptible strain well above its own MIC, at the clinical 
breakpoint concentration. Extrapolating this finding to the community, we hypothesize that within each $24 \mathrm{~h}$ period, CTX-M producers (and possibly other degraders) are selected for by cefotaxime and are then outcompeted by susceptible bacteria following antibiotic degradation. This means that resistant genotypes are likely to persist at even very low antibiotic concentrations, as they provide a benefit to the whole community; this effect has been modeled previously (19).

Selection for bla $a_{\text {СТX-M }}$ genes is likely due to a combination of clonal expansion of

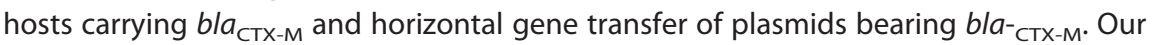
results are consistent with epidemiological data on beta-lactam resistance genes (35, $36)$, which document the rapid spread of bla status. In this study, $b / a_{\text {СTX-M }}$ genes were under stronger selection than a large diversity of other resistance genes, possibly due to lower fitness cost (either metabolic or due to genetic context) and/or due to more efficient degradation and a potential wider degradative capacity. For example, previous research found that the MICs of bla $a_{\mathrm{CTX}-\mathrm{M}^{-}}$ positive bacteria isolated from river sediment downstream of a wastewater treatment plant were in excess of $2,048 \mu \mathrm{g} / \mathrm{ml}$ (37). Additionally, many TEM and OXA betalactamases do not have the extended-spectrum degradative capability of CTX-M ESBLs $(35,36)$. We suggest that the ability of $b / a_{\text {СTX-M }}$ genes to outcompete other betalactamase genes at all studied concentrations may also have contributed to the pandemic spread of bla $a_{\text {CTX-M }}$ genes worldwide (35) and the replacement of other beta-lactamase variants (36).

The metagenome analyses showed that $\operatorname{ampC}$ genes were detected but not enriched by cefotaxime exposure. Overexpression of chromosomal ampC genes can increase levels of resistance to many antibiotics, including cefotaxime, but these genes were very rare within metagenomes and confer only low-level resistance up to $8 \mathrm{mg} /$ liter (38), suggesting that they do not play a significant role at the community level in this study (39). The metagenome analyses also showed that cefotaxime can also co-select for resistance to a range of antibiotic classes, even at subinhibitory cefotaxime concentrations. Co-occurrence of bla $a_{\mathrm{CTX}-\mathrm{M}}$ genes and aminoglycoside resistance has been reported previously and is confirmed here (36). High levels of co-selection also indicate the presence of multidrug resistant plasmids, via co-resistance (i.e., colocalization of multiple genes, of which only one needs to be under positive selection) (40).

The bacterial community analyses showed that cefotaxime had significant effects on community structure, even at subinhibitory concentrations, through elimination of several species as determined by LEfSe. The bacterial communities in all treatments comprised mainly of Gram-negative bacterial families, with $E$. coli being the most abundant species in all treatments. In wastewater, with a lower temperature and different nutritional composition, interspecies competition with other taxa could result in reduced $E$. coli abundance, which may be favored by the medium and temperature used in this study. However, E. coli is known to survive wastewater treatment and is used as a fecal indicator organism to assess water quality (41). Therefore, in wastewater, E. coli may still possess a competitive advantage. There was much greater variability between replicates (for all species other than E. coli) within exposed communities, indicative of potential founder effects on evolution within individual microcosms, again supporting the hypothesis that selection was acting at these concentrations. Worryingly, cefotaxime exposure enriched for well-known opportunistic Gram-negative pathogens, including $P$. aeruginosa, which readily infects immunocompromised individuals such as cystic fibrosis patients, and $A$. baumannii, which is most commonly associated with hospital-acquired infections (42). Enrichment for these opportunistic pathogens and human and gut commensals such as $B$. fragilis and $E$. faecalis under cefotaxime exposure may be due to intrinsic resistance, which is likely to result in enrichment within communities including susceptible strains.

In summary, our findings develop understanding of selection for antibiotic resistance by showing that the strength of selection for clinically important resistance genes in a community context can be equal across a very large antibiotic concentration 
gradient; in other words, we show that the strength of selection within a given selective space may be constant. Therefore, selection pressure below the MIC of susceptible bacteria may be as strong as selection between the MICs of susceptible and resistant bacteria (traditional selective window). We hypothesize that in our study, this observation is due to the community-wide benefit provided by resistant bacteria harboring degradative resistance mechanisms. Marked increases in common Gram-negative, opportunistic pathogens and co-selection for resistance to other antibiotic classes raise concerns about selection and co-selection for clinically relevant genes (such as $\left.b / a_{\text {СTX-M }}\right)$ in pathogenic hosts occurring in a wide range of ecologic compartments.

\section{MATERIALS AND METHODS}

Complex community collection, storage, and preparation. Domestic sewage influent from a wastewater treatment plant serving a small town was collected in October 2015. The treatment plant serves a population of 43,000 . Single-use aliquots were mixed in a 1:1 ratio with $20 \%$ glycerol, vortexed, and stored at $-80^{\circ} \mathrm{C}$. Before use, samples were spun down at $21,100 \times g$ for $10 \mathrm{~min}$, the supernatant was removed, and the pellet was resuspended twice in equal volumes of $0.85 \% \mathrm{NaCl}$ to prevent nutrient/ chemical carryover.

A pilot experiment (data not shown) was conducted to determine the appropriate density of the complex community inoculum by comparing growth over $24 \mathrm{~h}$ of different dilutions of inoculum at a range of antibiotic concentrations in a 96-well plate. Following results from the pilot experiment, the $10 \%$ $(\mathrm{vol} / \mathrm{vol})$ wastewater inoculum was used for all further experiments using the complex community on the basis that it produced the tightest replicates at all the time points and the most reliable growth phases over $24 \mathrm{~h}$.

Selection experiments. Iso-Sensitest broth (Sigma) was inoculated with 10\% (vol/vol) of untreated wastewater. This was separated into 30-ml aliquots, and appropriate amounts of cefotaxime stock solution were added. Cefotaxime (Molekular) stocks were prepared in autoclaved and filtered $(0.22-\mu \mathrm{m})$ deionized water.

These 30-ml aliquots were further separated into 5 - $\mathrm{ml}$ aliquots, with 5 replicates for each of the cefotaxime assay concentrations: $2 \mathrm{mg} / \mathrm{liter}, 1 \mathrm{mg} / \mathrm{liter}$, and 500, 250, 125, 62.5, 31.25, 15.625, and $0 \mu \mathrm{g} /$ liter for the first experiment and 128, 64, 32, 16, 8, 4, 2, and $0 \mathrm{mg} /$ liter for the second experiment.

All replicates were immediately sampled for the day 0 sampling time point: 2 portions of $1 \mathrm{ml}$ of each replicate for each treatment were spun down at $21,100 \times g$ for $3 \mathrm{~min}$, the supernatant was removed, and pellet was resuspended in $1,000 \mu \mathrm{l} 20 \%$ glycerol followed by storage at $-80^{\circ} \mathrm{C}$. All other samples for DNA extraction were taken following each overnight incubation at $37^{\circ} \mathrm{C}$, with 180 -rpm shaking, as described above.

After each incubation, $50 \mu \mathrm{l}$ of each microcosm was inoculated into $5 \mathrm{ml}$ fresh medium with fresh antibiotic, and samples were taken as described above for a total of 8 days. Remaining cell suspensions were spun down and stored as described above at the end of each experiment.

Metagenome analyses. Three replicates were chosen at random from the no-antibiotic, $125 \mu \mathrm{g} /$ liter, $500 \mu \mathrm{g} / \mathrm{liter}$, and $2 \mathrm{mg} /$ liter treatments to undergo shotgun metagenome sequencing on the MiSeq2 v2 platform at University of Exeter Sequencing Service (ESS).

DNA was extracted from $1 \mathrm{ml}$ of frozen overnight culture using the Mo Bio extraction kit according to the manufacturer's instructions. DNA was cleaned and concentrated using AMPure beads. First, $2 \mu \mathrm{l}$ of $20 \mathrm{mg} / \mathrm{ml}$ RNase A (Qiagen) was added to $50 \mu \mathrm{l} \mathrm{DNA}$ and incubated for $10 \mathrm{~min}$ at $37^{\circ} \mathrm{C}$. Fifty microliters of AMPure beads was mixed with the DNA/RNase solution, mixed gently by pipetting, and incubated at room temperature for 5 to $10 \mathrm{~min}$. Following pulse centrifugation to collect droplets, tubes were placed on a magnetic stand and left until all beads had precipitated to the side of the tube. Supernatant was removed, and beads were washed two times with $300 \mu$ l freshly prepared $80 \%$ ethanol. Beads were air dried briefly (1 to $2 \mathrm{~min}$ ), resuspended in $10 \mu \mathrm{l} 10 \mathrm{mM}$ Tris- $\mathrm{HCl}$, and then incubated for another $10 \mathrm{~min}$ at $50^{\circ} \mathrm{C}$. Following pulse centrifugation and bead precipitation, DNA was transferred into a fresh tube and stored at $-20^{\circ} \mathrm{C}$ until library preparation and sequencing.

The 12 Nextera library preparations, quality control, sequencing, and primary sequencing analysis (including trimming reads of the barcodes) were performed by ESS. Data were then run through the ARGs-OAP (online analysis pipeline for antibiotic resistance genes detection from metagenome data using an integrated structured antibiotic resistance gene database) (28). This provides the abundance of different resistance gene classes and subtypes within these groups normalized by parts per million, $16 \mathrm{~S}$ rRNA copy number, and cell number. For all subsequent analysis, data normalized by 165 rRNA copy number were used to be in accordance with the qPCR data generated. Heat maps for resistance gene abundance were generated using pandas (43), Matplotlib (44), and Seaborn (45) Python packages for resistance gene class and beta-lactam resistance gene subtype, for averages from these three replicates.

$16 \mathrm{~S}$ rRNA sequences were extracted from the lllumina sequencing data as follows: first, forward and reverse reads were adapter trimmed using Skewer (46) in paired-end mode. FastQC (47) and MultiQC (48) verified successful adapter removal and that sequences were of acceptable quality before paired-end reads were combined with FLASH version 2 (49) with the maximum overlap set to 300. 16S rRNA sequences were extracted and assigned to bacterial species using MetaPhIAn2 (27). The resulting heat map of species relative abundance was generated using HClust2 using Bray-Curtis distance measurements between samples and features (species) (50), and overall species abundance across treatments was visualized with GraPhIAn (51). Linear discriminant analysis (LDA) effect size (LEfSe) analyses were 
TABLE 1 List of synthetic gene blocks used in the study, their DNA sequence, size in base pairs, and accession numbers used to for design

\begin{tabular}{|c|c|c|c|}
\hline Gene & Sequence & Size (bp) & Accession no \\
\hline $16 \mathrm{~S}$ & $\begin{array}{l}\text { ACGGTGAATACGTTCCCGGGCCTTGTACACACCGCCCGTCACACCATGGGAGTG } \\
\text { GGTTGCAAAAGAAGTAGGTAGCTTAACCTCGGGAGGGCGCTTACCACTITGTG } \\
\text { ATTCATGACTGGGGTGAAGTCGTAACAAGGTAACCG }\end{array}$ & 144 & СР018770.2 \\
\hline
\end{tabular}

performed, and results were visualized with LEfSe (52) to identify which species, if any, were enriched by a particular cefotaxime treatment.

qPCR analyses. Frozen samples were thawed, and DNA was extracted using the MBio UltraClean DNA extraction kit according to instructions. DNA was diluted $5 \times$ to $10 \times$ before use.

The qPCR conditions were optimized using primers from previous studies $(53,54): 10 \mu$ l Brilliant qPCR SYBR green master mix, $2 \mu \mathrm{l}$ primer pair (5 $\mu \mathrm{M}$ [each] forward and reverse primers for $16 \mathrm{~S}$ rRNA, and $9 \mu \mathrm{M}$ [each] forward and reverse CTX-M primers), $0.2 \mu \mathrm{l}$ bovine serum albumin (BSA) (20 mg/ml), $0.4 \mu \mathrm{l}$ ROX reference dye $(20 \mu \mathrm{M}), 5 \mu$ l diluted DNA template, and filtered, sterilized water to a total volume of $20 \mu \mathrm{l}$. The qPCR program for all reactions was $95^{\circ} \mathrm{C}$ for $3 \mathrm{~min}$, followed by 40 cycles of $95^{\circ} \mathrm{C}$ for $10 \mathrm{~s}$ and $60^{\circ} \mathrm{C}$ for $30 \mathrm{~s}$. bla $a_{\mathrm{CTX}-\mathrm{M}}$ copy number was divided by $16 \mathrm{~S}$ rRNA copy number to determine bla $a_{\mathrm{CTX}-\mathrm{M}}$ gene/16S rRNA, a proxy for bla $a_{\text {CTX-M }}$ prevalence.

gBlock synthetic genes (Integrated DNA Technologies [Table 1]) were used as qPCR standards; these were resuspended in Tris-EDTA (TE) buffer according to the manufacturer's instructions and were stored at $-80^{\circ} \mathrm{C}$.

Standards were $10 \times$ serially diluted in TE buffer and stored at $-20^{\circ} \mathrm{C}$ before use. Every PCR plate was always run with 5 serial dilutions of standards in duplicate (and a duplicate negative control). Provided that the efficiency for the reaction was between $90 \%$ and $110 \%$, the average threshold cycle $\left(C_{T}\right)$ for the duplicate technical replicates for each sample was used to calculate the copy number based on a "gold standard" standard series, where the DNA concentration had been quantified by Qubit and the copy number per microliter quantified immediately prior to cycling.

Data analyses. All statistics were performed in RStudio (55). Selection coefficients were used to determine MSC, with the following equation, as described previously $(3):\{\ln [R(t) / R(0)]\} /(t)$, where $R$ is resistance prevalence, $t$ is time in days, and $R(0)$ is resistance prevalence at time zero. The MSC is estimated by the line of best-fit $x$-axis intersect. Figures were generated with various Python packages (43-45).

Chemical extraction/analyses. Complex community microcosms were sampled at the day 0 point and after the first $24 \mathrm{~h}$. Antibiotic stocks were also quantified.

The extraction procedure was as follows: $400 \mu \mathrm{l}$ of culture was mixed with $400 \mu \mathrm{l} \mathrm{HiPerChromosolv}$ acetonitrile in a 2-ml 96-well plate and spun at 3,500 rpm for $30 \mathrm{~min}$. One hundred microliters of this supernatant was then mixed with $900 \mu$ l of a 1:4 ratio of acetonitrile to high-pressure liquid chromatography (HPLC)-grade water in a fresh plate and stored in the refrigerator. Antibiotic stocks were diluted to a final concentration of $100 \mathrm{ng} /$ liter in 1:4 acetonitrile. Extraction mixtures were kept at $4^{\circ} \mathrm{C}$ until processing.

Each concentration from the evolution experiment had a minimum of two chemical replicates from at least two of the biological replicates. Stocks were single replicate only.

Antibiotic degradation experiment. Washed, untreated wastewater was diluted in 25-ml IsoSensitest broth aliquots spiked with cefotaxime concentrations of $0,15.625,31.25,62.5,125,250$, and $500 \mu \mathrm{g} /$ liter or $2 \mathrm{mg} / \mathrm{liter}$. A sterile control at the same concentrations was also prepared. These were incubated at $37^{\circ} \mathrm{C}$, with 180-rpm shaking in between samplings. Chemical extractions (see below) and destructive sampling for optical density (OD) readings were performed at time zero and then every $3 \mathrm{~h}$ for $24 \mathrm{~h}$. OD measurements were carried out in a spectrophotometer (Jenway, United Kingdom) at the same time points at $600 \mathrm{~nm}$. Any samples with OD readings of a value greater than 1 were diluted $10 \times$ in Iso-Sensitest broth and then remeasured.

Supernatant experiment. E. coli strains J53 and NCTC 13451 were grown overnight at $37^{\circ} \mathrm{C}$ with shaking at $180 \mathrm{rpm}$ in Iso-Sensitest broth (supplemented with $2 \mathrm{mg} /$ liter cefotaxime for NCTC 13451). This concentration was chosen on the basis that it was greater than the J53 MIC (>250 $\mu$ g/liter and $<500 \mu \mathrm{g} /$ /iter, determined by microdilution assay [56]), that it would be fully degraded in a betalactamase-producing community (according to the overnight degradation experiment), and because it is the clinical breakpoint concentration for Enterobacteriaceae (23). The supernatants from both overnight cultures were spun down at $21,000 \times g$ for 2 min twice and then filtered through a $0.22-\mu \mathrm{m}$ filter. J53 was inoculated at a starting optical density $(600 \mathrm{~nm})$ of 0.01 into fresh Iso-Sensitest broth amended with $2 \mathrm{mg} / \mathrm{liter}$ and $\mathrm{J} 53$ or NCTC 13451 supernatant (12.5\% [vol/vol]). Controls included a blank control (to check general aseptic technique), broth with each supernatant (to verify that the supernatant was sterile), and $J 53$ in broth both with and without antibiotic (to deduce effects of nutrient dilution). 
SUPPLEMENTAL MATERIAL

Supplemental material for this article may be found at https://doi.org/10.1128/mBio

.00969-18.

FIG S1, DOCX file, $0.3 \mathrm{MB}$.

FIG S2, DOCX file, $0.1 \mathrm{MB}$.

FIG S3, DOCX file, $0.1 \mathrm{MB}$.

FIG S4, DOCX file, $0.04 \mathrm{MB}$.

FIG S5, DOCX file, $0.04 \mathrm{MB}$.

FIG S6, DOCX file, $0.04 \mathrm{MB}$.

FIG S7, DOCX file, $0.05 \mathrm{MB}$.

FIG S8, DOCX file, $0.1 \mathrm{MB}$.

TABLE S1, DOCX file, $0.01 \mathrm{MB}$.

\section{ACKNOWLEDGMENTS}

Aimee K. Murray was supported by a BBSRC/AZ CASE Studentship, BB/L502509/1.

Lihong Zhang was supported by Natural Environment Research Council grant NE/ M011259/1. Chemical quantification was performed at the University of Exeter Streatham Campus by Maciek Trnzadel and Malcolm Hetheridge, cofunded by Astra Zeneca Global SHE and the University of Exeter.

\section{REFERENCES}

1. Review on Antimicrobial Resistance. 2014. Antimicrobial resistance: tackling a crisis for the health and wealth of nations. Review on Antimicrobial Resistance, London, United Kingdom.

2. Review on Antimicrobial Resistance. 2015. Antimicrobials in agriculture and the environment: reducing unnecessary use and waste. Review on Antimicrobial Resistance, London, United Kingdom.

3. Gullberg E, Cao S, Berg OG, Ilbäck C, Sandegren L, Hughes D, Andersson DI. 2011. Selection of resistant bacteria at very low antibiotic concentrations. PLoS Pathog 7:e1002158. https://doi.org/10.1371/journal.ppat .1002158 .

4. Andersson DI, Hughes D. 2012. Evolution of antibiotic resistance at non-lethal drug concentrations. Drug Resist Updat 15:162-172. https:// doi.org/10.1016/j.drup.2012.03.005.

5. Gullberg E, Albrecht LM, Karlsson C, Sandegren L, Andersson DI. 2014. Selection of a multidrug resistance plasmid by sublethal levels of antibiotics and heavy metals. mBio 5:e01918-14. https://doi.org/10.1128/mBio .01918-14.

6. Negri MC, Lipsitch M, Blázquez J, Levin BR, Baquero F. 2000. Concentration-dependent selection of small phenotypic differences in TEM beta-lactamase-mediated antibiotic resistance. Antimicrob Agents Chemother 44:2485-2491. https://doi.org/10.1128/AAC.44.9.2485-2491 .2000 .

7. Negri MC, Morosini MI, Baquero MR, del Campo R, Blázquez J, Baquero F. 2002. Very low cefotaxime concentrations select for hypermutable Streptococcus pneumoniae populations. Antimicrob Agents Chemother 46:528-530. https://doi.org/10.1128/AAC.46.2.528-530.2002.

8. Bengtsson-Palme J, Larsson DG. 2016. Concentrations of antibiotics predicted to select for resistant bacteria: proposed limits for environmental regulation. Environ Int 86:140-149. https://doi.org/10.1016/j .envint.2015.10.015.

9. Baquero F, Coque TM. 2014. Widening the spaces of selection: evolution along sublethal antimicrobial gradients. mBio 5:e02270-14. https://doi .org/10.1128/mBio.02270-14.

10. Volkmann H, Schwartz T, Bischoff P, Kirchen S, Obst U. 2004. Detection of clinically relevant antibiotic-resistance genes in municipal wastewater using real-time PCR (TaqMan). J Microbiol Methods 56:277-286. https:// doi.org/10.1016/j.mimet.2003.10.014.

11. Schwartz T, Kohnen W, Jansen B, Obst U. 2003. Detection of antibioticresistant bacteria and their resistance genes in wastewater, surface water, and drinking water biofilms. FEMS Microbiol Ecol 43:325-335. https://doi.org/10.1111/j.1574-6941.2003.tb01073.x.

12. Hultman J, Tamminen M, Pärnänen K, Cairns J, Karkman A, Virta M. 2018. Host range of antibiotic resistance genes in wastewater treatment plant influent and effluent. FEMS Microbiol Ecol 94:fiy038. https://doi.org/10 $.1093 /$ femsec/fiy038.
13. Karkman A, Do TT, Walsh F, Virta MPJ. 2018. Antibiotic-resistance genes in waste water. Trends Microbiol 26:220-228. https://doi.org/10.1016/j .tim.2017.09.005.

14. Lundström SV, Östman $M$, Bengtsson-Palme J, Rutgersson $C$, Thoudal $M$, Sircar T, Blanck H, Eriksson KM, Tysklind M, Flach CF, Larsson DGJ. 2016. Minimal selective concentrations of tetracycline in complex aquatic bacterial biofilms. Sci Total Environ 553:587-595. https://doi.org/10 .1016/j.scitotenv.2016.02.103.

15. WHO. 2011. Critically important antimicrobials for human medicine. Advisory Group on Integrated Surveillance of Antimicrobial Resistance (AGISAR), World Health Organization, Geneva, Switzerland.

16. WHO. 2015. 19th WHO model list of essential medicines. World Health Organization, Geneva, Switzerland.

17. WHO. 2017. Model list of essential medicines. World Health Organization, Geneva, Switzerland.

18. Livermore DM. 1995. Beta-lactamases in laboratory and clinical resistance. Clin Microbiol Rev 8:557-584.

19. Dugatkin LA, Perlin M, Atlas R. 2003. The evolution of group-beneficial traits in the absence of between-group selection. J Theor Biol 220:67-74. https://doi.org/10.1006/jtbi.2003.3149.

20. Medaney F, Dimitriu T, Ellis RJ, Raymond B. 2016. Live to cheat another day: bacterial dormancy facilitates the social exploitation of betalactamases. ISME J 10:778-787. https://doi.org/10.1038/ismej.2015.154.

21. Yurtsev EA, Chao HX, Datta MS, Artemova T, Gore J. 2013. Bacterial cheating drives the population dynamics of cooperative antibiotic resistance plasmids. Mol Syst Biol 9:683. https://doi.org/10.1038/msb .2013.39.

22. Bottery MJ, Wood AJ, Brockhurst MA. 2016. Selective conditions for a multidrug resistance plasmid depend on the sociality of antibiotic resistance. Antimicrob Agents Chemother 60:2524-2527. https://doi.org/10 1128/AAC.02441-15.

23. EUCAST. 2014. Breakpoint tables for interpretation of MICs and zone diameters, version 4.0.

24. Gómez MJ, Malato O, Ferrer I, Agüera A, Fernández-Alba AR. 2007. Solid-phase extraction followed by liquid chromatography-time of flight-mass spectrometry to evaluate pharmaceuticals in effluents. A pilot monitoring study. J Environ Monit 9:718-729. https://doi.org/10 .1039/b702844j.

25. Umweltbundesamt. 2016. Pharmaceuticals in the environment. Umweltbundesamt, Dessau-Roßlau, Germany.

26. Homem V, Santos L. 2011. Degradation and removal methods of antibiotics from aqueous matrices - a review. J Environ Manage 92: 2304-2347. https://doi.org/10.1016/j.jenvman.2011.05.023.

27. Truong DT, Franzosa EA, Tickle TL, Scholz M, Weingart G, Pasolli E, Tett A, Huttenhower C, Segata N. 2015. MetaPhIAn2 for enhanced metag- 
enomic taxonomic profiling. Nat Methods 12:902-903. https://doi.org/ 10.1038/nmeth.3589.

28. Yang Y, Jiang X, Chai B, Ma L, Li B, Zhang A, Cole JR, Tiedje JM, Zhang T. 2016. ARGs-OAP: online analysis pipeline for antibiotic resistance genes detection from metagenomic data using an integrated structured ARG-database. Bioinformatics 32:2346-2351. https://doi.org/10 .1093/bioinformatics/btw136.

29. Das Gupta V. 1984. Stability of cefotaxime sodium as determined by high-performance liquid chromatography. J Pharm Sci 73:565-567. https://doi.org/10.1002/jps.2600730434.

30. Woodford N, Carattoli A, Karisik E, Underwood A, Ellington MJ, Livermore DM. 2009. Complete nucleotide sequences of plasmids pEK204, pEK499, and pEK516, encoding CTX-M enzymes in three major Escherichia coli lineages from the United Kingdom, all belonging to the international O25:H4-ST131 cone. Antimicrob Agents Chemother 53:4472-4482. https://doi.org/10.1128/AAC.00688-09.

31. CDC. 2013. Antibiotic resistance threats in the United States, 2013. Centers for Disease Control and Prevention, Atlanta, GA.

32. Gulkowska A, Leung HW, So MK, Taniyasu S, Yamashita N, Yeung LW, Richardson BJ, Lei AP, Giesy JP, Lam PK. 2008. Removal of antibiotics from wastewater by sewage treatment facilities in Hong Kong and Shenzhen, China. Water Res 42:395-403. https://doi.org/10.1016/j.watres.2007 .07.031.

33. Pena-Miller R, Laehnemann D, Jansen G, Fuentes-Hernandez A, Rosenstiel P, Schulenburg H, Beardmore R. 2013. When the most potent combination of antibiotics selects for the greatest bacterial load: the smile-frown transition. PLoS Biol 11:e1001540. https://doi.org/10.1371/ journal.pbio.1001540.

34. Llewelyn MJ, Fitzpatrick JM, Darwin E, Tonkin-Crine S, Gorton C, Paul J, Peto TEA, Yardley L, Hopkins S, Walker AS. 2017. The antibiotic course has had its day. BMJ 358:j3418. https://doi.org/10.1136/bmj.j3418.

35. Cantón R, Coque TM. 2006. The CTX-M beta-lactamase pandemic. Curr Opin Microbiol 9:466-475. https://doi.org/10.1016/j.mib.2006.08.011.

36. Cantón R, González-Alba JM, Galán JC. 2012. CTX-M enzymes: origin and diffusion. Front Microbiol 3:110. https://doi.org/10.3389/fmicb.2012 .00110 .

37. Amos GC, Hawkey PM, Gaze WH, Wellington EM. 2014. Waste water effluent contributes to the dissemination of CTX-M-15 in the natural environment. J Antimicrob Chemother 69:1785-1791. https://doi.org/10 $.1093 / \mathrm{jac} / \mathrm{dku} 079$.

38. Peter-Getzlaff S, Polsfuss S, Poledica M, Hombach M, Giger J, Böttger EC, Zbinden R, Bloemberg GV. 2011. Detection of AmpC beta-lactamase in Escherichia coli: comparison of three phenotypic confirmation assays and genetic analysis. J Clin Microbiol 49:2924-2932. https://doi.org/10.1128/ JCM.00091-11.
39. Jacoby GA. 2009. AmpC beta-lactamases. Clin Microbiol Rev 22:161-182. https://doi.org/10.1128/CMR.00036-08.

40. Baker-Austin C, Wright MS, Stepanauskas R, McArthur JV. 2006. Coselection of antibiotic and metal resistance. Trends Microbiol 14: 176-182. https://doi.org/10.1016/j.tim.2006.02.006.

41. Ashbolt NJ, Grabow WOK, Snozzi M. 2001. Indicators of microbial water quality, p 289-316. In Fewtrell L, Bartram J (ed), Water quality: guidelines, standards and health. IWA Publishing, London, United Kingdom.

42. Howard A, O'Donoghue M, Feeney A, Sleator RD. 2012. Acinetobacter baumannii: an emerging opportunistic pathogen. Virulence 3:243-250. https://doi.org/10.4161/viru.19700.

43. McKinney W. 2010. Data structures for statistical computing in Python, $p$ 51-56. In van der Walt S, Millman J (ed), Proceedings of the 9th Python In Science Conference.

44. Hunter JD. 2007. Matplotlib: a 2D graphics environment. Comput Sci Eng 9:90-95. https://doi.org/10.1109/MCSE.2007.55.

45. Waskom M. 2016. Seaborn: v0.7.1 (June 2016).

46. Jiang H, Lei R, Ding SW, Zhu S. 2014. Skewer: a fast and accurate adapter trimmer for next-generation sequencing paired-end reads. BMC Bioinformatics 15:182. https://doi.org/10.1186/1471-2105-15-182.

47. Andrews S. 2010. FastQC: a quality control tool for high throughput sequence data.

48. Ewels $P$, Magnusson M, Lundin S, Käller M. 2016. MultiQC: summarize analysis results for multiple tools and samples in a single report. Bioinformatics 32:3047-3048. https://doi.org/10.1093/bioinformatics/btw354.

49. Magoč T, Salzberg SL. 2011. FLASH: fast length adjustment of short reads to improve genome assemblies. Bioinformatics 27:2957-2963. https:// doi.org/10.1093/bioinformatics/btr507.

50. Segata N. 2018. HClust2.

51. Asnicar F, Weingart G, Tickle TL, Huttenhower C, Segata N. 2015. Compact graphical representation of phylogenetic data and metadata with GraPhIAn. PeerJ 3::e1029. https://doi.org/10.7717/peerj.1029.

52. Segata N, Izard J, Waldron L, Gevers D, Miropolsky L, Garrett WS, Huttenhower C. 2011. Metagenomic biomarker discovery and explanation. Genome Biol 12:R60. https://doi.org/10.1186/gb-2011-12-6-r60.

53. Birkett Cl, Ludlam HA, Woodford N, Brown DF, Brown NM, Roberts MT, Milner N, Curran MD. 2007. Real-time TaqMan PCR for rapid detection and typing of genes encoding CTX-M extended-spectrum $\beta$-lactamases. J Med Microbiol 56:52-55. https://doi.org/10.1099/jmm.0.46909-0.

54. Czekalski N, Gascón Díez E, Bürgmann H. 2014. Wastewater as a point source of antibiotic-resistance genes in the sediment of a freshwater lake. ISME J 8:1381-1390. https://doi.org/10.1038/ismej.2014.8.

55. RStudio. 2015. RStudio: integrated development for R. RStudio, Inc, Boston, MA

56. Andrews JM. 2001. Determination of minimum inhibitory concentrations. J Antimicrob Chemother 48:5-16. 